\title{
Indian Ocean Subtropical Mode Water: its water characteristics and spatial distribution
}

\author{
T. Tsubouchi, T. Suga, and K. Hanawa \\ Department of Geophysics, Tohoku University, Sendai, Japan \\ Received: 20 March 2009 - Published in Ocean Sci. Discuss.: 21 April 2009 \\ Revised: 4 December 2009 - Accepted: 4 January 2010 - Published: 22 January 2010
}

\begin{abstract}
We have improved a basic description (water characteristics and spatial distribution) of the Indian Ocean Subtropical Mode Water (IOSTMW) using an isopycnally averaged three-dimensional hydrographic dataset. Two mode waters and corresponding wintertime mixed layer depth maxima were observed north of the subtropical front (STF) in the South Indian Ocean: IOSTMW (within 25.8-26.2 $\sigma_{\theta}$ ) in the region of $28-45^{\circ} \mathrm{E}$ and another subtropical mode water in the subtropical gyre (within 26.4-26.7 $\sigma_{\theta}$ ) in the $60-80^{\circ} \mathrm{E}$ longitudinal band. Through careful examination of the spatial distribution and water characteristics of a core in the layer of minimum vertical temperature gradient (LMVTG), we identified that a mass of LMVTG corresponds to IOSTMW. The average water characteristics of the IOSTMW during approximately $1960-2004$ were $16.54 \pm 0.49^{\circ} \mathrm{C}, 35.51 \pm 0.04 \mathrm{psu}$ and $26.0 \pm 0.1 \sigma_{\theta}$. The IOSTMW distribution area was estimated to be $25-50^{\circ} \mathrm{E}, 27-38^{\circ} \mathrm{S}$. The formation region and approximate water characteristics of the second subtropical mode water were also estimated. Its probable formation region was $37-42^{\circ} \mathrm{S}, 60-80^{\circ} \mathrm{E}$ and north of the STF, with approximate water characteristics of $12.84 \pm 0.57^{\circ} \mathrm{C}$, $35.17 \pm 0.11 \mathrm{psu}$ and $26.57 \pm 0.04 \sigma_{\theta}$.
\end{abstract}

\section{Introduction}

Mode waters, which are characterised by thermostads or pycnostads, are remnants of the deepest winter mixed layers and are widely distributed in the world's interior ocean (Hanawa and Talley, 2001). Since the deepest mixed layers contain the memories of accumulated atmospheric forcing, such as winter cooling and wind stress, the mode waters are thought to transmit these memories to the interior ocean below the

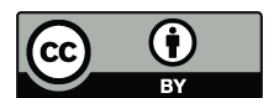

Correspondence to: T. Tsubouchi (tt2r07@noc.soton.ac.uk) winter mixed layer via the subduction mechanism (Marshall et al., 1993). Some of them could affect the sea surface temperature in the following winter through the re-emergence mechanism (Hanawa and Sugimoto, 2004).

Two mode waters have been widely recognized in the South Indian Ocean: Sub-Antarctic Mode Water (SAMW; McCartney, 1977, 1982) and Indian Ocean Subtropical Mode Water (IOSTMW; Olson et al., 1992). SAMW is distributed in the circumpolar Southern Ocean, north of the subantarctic front (SAF). It is formed in the subantarctic zone (SAZ) which is bounded by the subtropical front (STF) and the SAF. Since SAMW is the dominant mode water in the South Indian Ocean, its distribution area and water characteristics have been widely described (Fine, 1993; Toole and Warren, 1993; Wong, 2005). Based on the Argo data, Wong (2005) showed that South Indian Ocean SAMW occupies a density range within $26.5-26.9 \sigma_{\theta}$ and its water characteristics gradually becomes colder, fresher and denser from $60^{\circ} \mathrm{E}$ to $115^{\circ} \mathrm{E}$. Winter mixed layer in the SAZ develops deeper than $300 \mathrm{~m}$ in $80-120^{\circ} \mathrm{E}$, where the $\mathrm{SAZ}$ widens east of the Kerguelen Plateau (Wong, 2005; Sallee et al., 2006; Aoki et al., 2007). This increase of MLD leads to the injection of a thick layer of SAMW of densities greater than $26.7 \sigma_{\theta}$ into the eastern South Indian Ocean. It spreads anticlockwise around the outer northeastern rim of the subtropical gyre (MacCarthy and Talley, 1999; Wong, 2005). The formation mechanism of SAMW has also been studied (Rintoul and England, 2002; Sallee et al., 2006). On the other hand, our knowledge of IOSTMW is still limited. Olson et al. (1992) noted a pycnostad with water characteristics of $17.6^{\circ} \mathrm{C}$ and $35.56 \mathrm{psu}$ which was distributed south of the African continent as a counterpart to the STMW in the North Atlantic, using Agulhas Retroflection Cruise (ARC) data. The ARC was conducted south of the African continent $\left(34-42^{\circ} \mathrm{S}, 13-26^{\circ} \mathrm{E}\right)$ from November to December 1983. Since then, several studies have provided fragmentary descriptions of the IOSTMW based on $32^{\circ} \mathrm{S}$ sectional observations from November to

Published by Copernicus Publications on behalf of the European Geosciences Union. 
December 1987 (Fine, 1993; Toole and Warren, 1993) and in March 2002 (McDonagh et al., 2005). Summarizing their description, IOSTMW was observed west of $40^{\circ} \mathrm{E}$ with water mass properties around $17^{\circ} \mathrm{C}, 35.6 \mathrm{psu}$ and $26.0 \sigma_{\theta}$ along the section. Recently, a deep mixed layer has been reported north of the STF in the $60-80^{\circ}$ E longitude band, based on the Argo data and an ocean general circulation model (Wong, 2005; Aoki et al., 2007). McDonagh et al. (2005) also suggested that mode water with $12.0-14.0^{\circ} \mathrm{C}$ at $70^{\circ} \mathrm{E}$ along the $32^{\circ} \mathrm{S}$ hydrographic line is subtropical, rather than subantarctic. However, the relationship between this mode water and IOSTMW is still unclear. Specifically, it is still vague how their water characteristics, distribution area and formation area relate to each other.

In this paper, we improve the basic description of the IOSTMW, such as its water characteristics and spatial distributions using an isopycnally averaged three-dimensional hydrographic dataset. According to the STMW definition of Hanawa and Talley (2001), we defined IOSTMW as the mode water adjacent to the subtropical western boundary currents with a single mode of water characteristics. From this point-of-view, the relationships between several mode waters in the Indian Ocean subtropical gyre (north of the STF) were sorted out. Section 2 describes the data and methods used in this study. Section 3 describes the winter mixed layer depth (MLD) in the South Indian Ocean and a zonal section along $35.5^{\circ} \mathrm{S}$ in order to distinguish the various mode waters. In Sect. 4, the relationships among these mode waters are carefully examined and the water characteristics of IOSTMW are calculated. Section 5 gives the spatial distribution of IOSTMW. Section 6 provides a conclusion.

\section{Data and methods}

We used the temperature and salinity data of the Indian Ocean HydroBase climatology (IOHB; Kobayashi and Suga, 2006) to investigate the interior South Indian Ocean. Because the HydroBase was constructed by averaging the original profile data isopycnally, the density structure was generally better reproduced than that of previous climatological data, especially around strong density fronts. Kobayashi and Suga (2006) showed that the IOHB has more realistic density stratification around the Antarctic Circumpolar Current (ACC) than the World Ocean Atlas 2001 (Stephens et al., 2002; Boyer et al., 2002). The IOHB climatology is provided on a $1^{\circ} \times 1^{\circ}$ (latitude $\times$ longitude) horizontal grid at standard depths from the surface to the bottom. The standard depth data were interpolated to $10 \mathrm{~m}$ vertical intervals using Akima's shape-preserving local spline method (Akima, 1970). The original monthly climatology data were averaged over January, February and March to calculate a summer mean climatology in the South Indian Ocean.
The combined dataset based on the Argo data and the World Ocean Circulation Experiment Southern Ocean database (SODB) was analysed to examine the spatial distribution of MLD in September. MLD was defined from individual profiles with a density difference criterion, difference of $0.03 \sigma_{\theta}$ from the near surface density. Calculated MLDs were then interpolated using the Ridgeway et al. (2002) technique. See Sallee et al. (2008) for the detailed procedures. The positions of the STF and the SAF were defined by Orsi et al. (1995).

We focused on the structure of the layer of minimum vertical temperature gradient (LMVTG) to investigate the remnant of the winter mixed layer using summer temperature data. The deep winter mixed layer is capped by the seasonal thermocline during the heating season. As a result, the LMVTG is generally formed between the seasonal and permanent thermoclines in summer. Hence, we were able to investigate the water originating from the winter mixed layer by detecting the LMVTG in the upper ocean temperature structure. The reason we focused on LMVTG instead of the minimum of potential vorticity (PV) will be shown in the next section.

The vertical temperature gradient $(d T / d z)$ was calculated the temperature difference between the adjacent grid points below and above (their depth difference was $20 \mathrm{~m}$ ). The LMVTG was defined as a minimum $d T / d z$ layer thicker than $50 \mathrm{~m}$. LMVTG was only detected when both the upper boundary of LMVTG and the lower boundary of LMVTG exceeded the threshold of $d T / d z$. The summer surface mixed layer was not detected as LMVTG because there is no temperature stratification above the surface mixed layer. The core of the LMVTG was defined as the depth at which the absolute minimum of $d T / d z$ occurred for each profile. The core preserves the best record of the wintertime mixed layer conditions because it is likely to have suffered the least modification. Therefore, the water characteristics of the LMVTG core could be regarded as typical water characteristics of the LMVTG.

STMW is defined in two ways: mode water which is associated with the subtropical western boundary currents, or mode water which is located north of the STF. Following the STMW definition of Hanawa and Talley (2001), we defined IOSTMW as the mode water adjacent to the Agulhas currents with single mode of water characteristics. We confirmed the existence of IOSTMW by examining whether

- a mass of LMVTG was widely distributed over the western part of the subtropical gyre, and

- its water characteristics formed a modal class of temperature and salinity for the regional area census. 
(a) MLD (m)

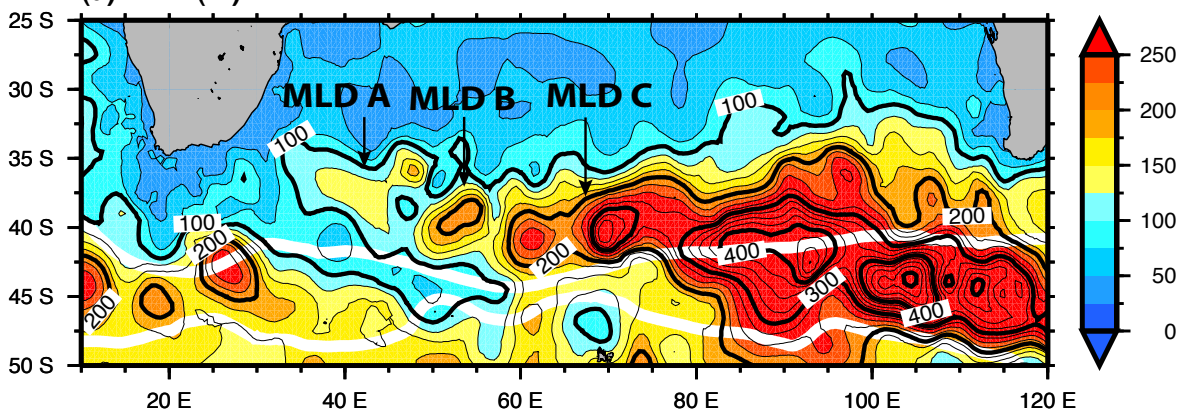

(b) mixed layer density $\left(\mathrm{kg} \mathrm{m}^{-3}\right)$

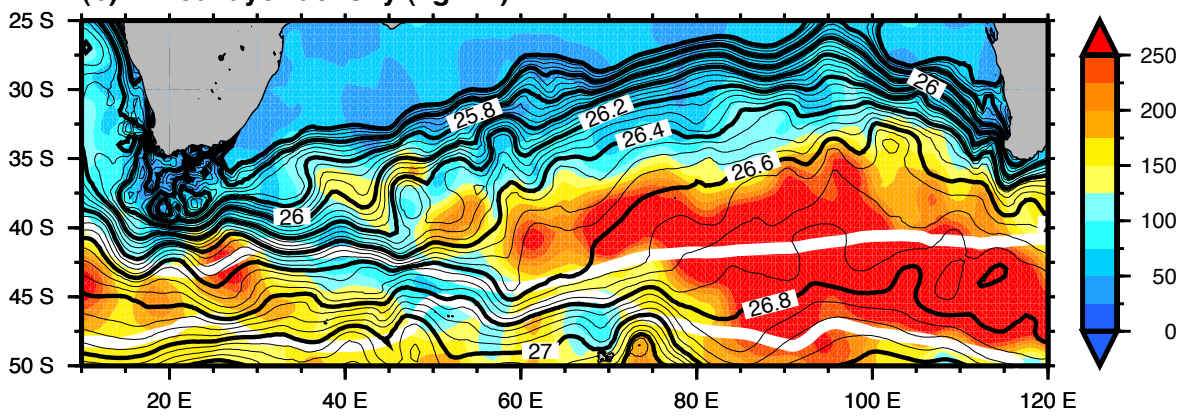

(c) mixed layer temperature $\left({ }^{\circ} \mathrm{C}\right)$

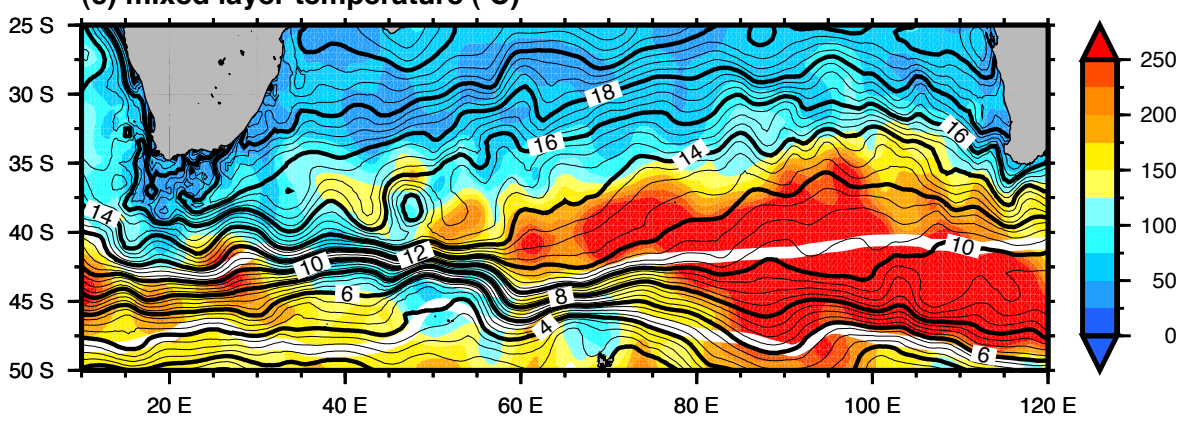

Fig. 1. Distribution of (a) MLD (contour interval $(\mathrm{CI})=25 \mathrm{~m}$ ), (b) mixed layer density (black contour; $\mathrm{CI}=0.05 \mathrm{~kg} \mathrm{~m}^{-3}$ ) superposed on MLD ( $\mathrm{m}$; coloured shade) and (c) mixed layer temperature (black contour; $\mathrm{CI}=0.5^{\circ} \mathrm{C}$ ) superposed on MLD (m; coloured shade). STF and SAF are shown in white contours.

\section{Mixed layer depth distribution and hydrographic line}

Figure 1 shows the spatial distribution of MLD in September and the positions of the STF and the SAF. Deep MLD (deeper than $300 \mathrm{~m}$ ) related to SAMW was observed in the $\mathrm{SAZ}$ in $80-120^{\circ} \mathrm{E}$ with $26.75-26.90 \sigma$. This characteristic agrees with previous studies (Wong, 2005; Sallee et al., 2006; Aoki et al., 2007). Three MLD maxima were observed north of the STF: A maximum around $125 \mathrm{~m}$ with $25.85-26.20 \sigma$ in $35-38^{\circ} \mathrm{S}$ and $35-50^{\circ} \mathrm{E}$ (MLD A), a maximum greater than $150 \mathrm{~m}$ with $26.25-26.40 \sigma$ in $37-42^{\circ} \mathrm{S}$ and $47-58^{\circ} \mathrm{E}$ (MLD B) and a maxima greater than $200 \mathrm{~m}$ with $26.40-26.65 \sigma$ in $37-42^{\circ} \mathrm{S}$ and $58-80^{\circ} \mathrm{E}$ (MLD C). The density and temperature contours were widened in these MLD maxima areas. This is a favourable condition for mode water formation. A wider area of similar sea surface density and temperature with deeper MLD produces larger mode water volume with specific density and temperature classes. The distribution area of MLD C was recently identified by Wong (2005) and Aoki et al. (2007) and the temperature range of MLD C $\left(12-14{ }^{\circ} \mathrm{C}\right)$ corresponds fairly well to the temperature range of mode water $\left(12.0-14.0^{\circ} \mathrm{C}\right)$ observed at $70^{\circ} \mathrm{E}$ along the $32^{\circ} \mathrm{S}$ hydrographic line (McDonagh et al., 2005).

Figure $2 \mathrm{a}$ and $2 \mathrm{~b}$ show three LMVTGs along $35.5^{\circ} \mathrm{S}$ longitudinal section on $25.8-26.2 \sigma_{\theta}$ in $28-45^{\circ} \mathrm{E}$ (LMVTG A), on $26.4-26.7 \sigma_{\theta}$ in $50-70^{\circ} \mathrm{E}$ (LMVTG B) and on 26.6$26.9 \sigma_{\theta}$ in $70-100^{\circ} \mathrm{E}$ (LMVTG C). Similar characteristics were observed in other sections between $33.5-38.5^{\circ} \mathrm{S}$. The density ranges of these LMVTGs corresponded to the density ranges of the MLD maxima: LMVTG A corresponded to MLD A, LMVTG B corresponded to MLD C, LMVTG C corresponded to the MLD maxima in the SAZ. No LMVTG corresponded to the density range of MLD B. Therefore, there are likely three mode waters in the South Indian Ocean: 
(a) $\mathrm{dT} / \mathrm{dz}$ vs depth

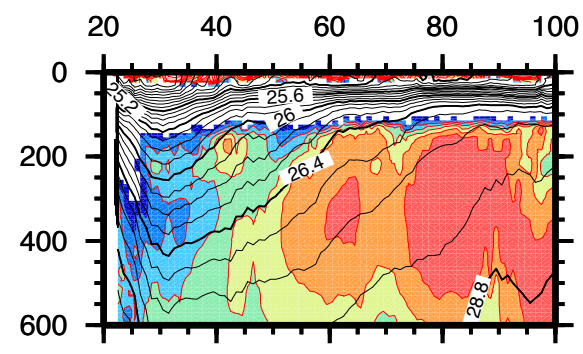

(d) salinity vs depth

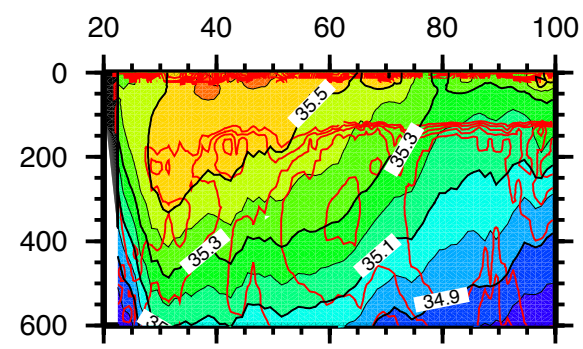

(b) $d T / d z$ vs pot. dens.

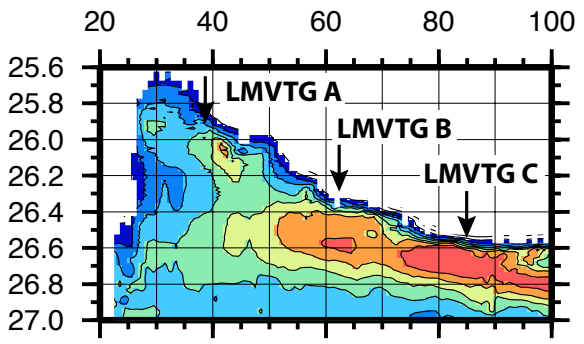

(e) dS/dz vs pot. dens.

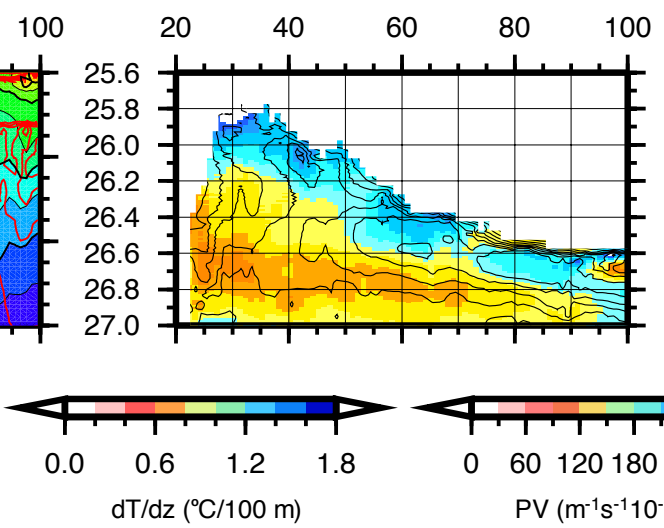

$60 \quad 80$ (c) PV vs pot. dens.

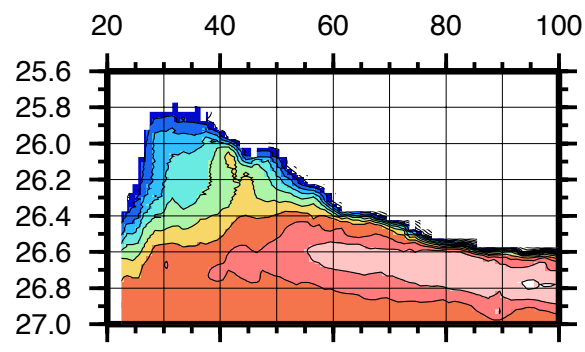

(f) $\mathrm{dS} / \mathrm{dz}$ vs pot. dens.

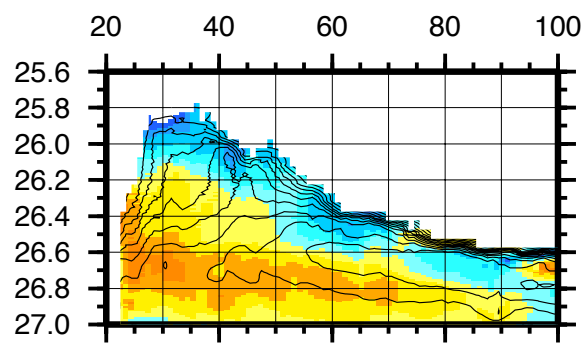

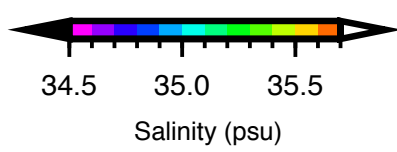
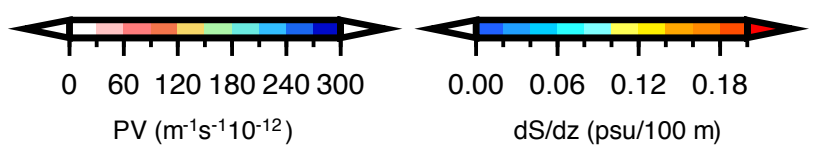

Fig. 2. The $35.5^{\circ} \mathrm{S}$ longitudinal section of (a) potential density (black contours; $\mathrm{CI}=0.1 \mathrm{~kg} \mathrm{~m}^{-3}$ ) with $d T / d z$ (colored shade; $\left.\mathrm{CI}=0.2^{\circ} \mathrm{C} / 100 \mathrm{~m}\right)$ versus depth $(\mathrm{m}),(\mathbf{b}) d T / d z\left(\mathrm{CI}=0.2^{\circ} \mathrm{C} / 100 \mathrm{~m}\right)$ versus potential density $\left(\mathrm{kg} \mathrm{m}^{-3}\right),(\mathbf{c}) \mathrm{PV}\left(\mathrm{CI}=30 \times 10^{-12} \mathrm{~m}^{-1} \mathrm{~s}^{-1}\right)$ versus potential density $\left(\mathrm{kg} \mathrm{m}^{-3}\right)$, (d) $d T / d z$ (red contours; $\mathrm{CI}=0.2^{\circ} \mathrm{C} / 100 \mathrm{~m}$ ) with salinity (colored shade; $\mathrm{CI}=0.1 \mathrm{psu}$ ) versus depth (m), (e) $d T / d z$ (black contours; $\mathrm{CI}=0.2^{\circ} \mathrm{C} / 100 \mathrm{~m}$ ) with $d S / d z$ (psu/100 m; colored shade) versus potential density $\left(\mathrm{kg} \mathrm{m}^{-3}\right.$ ) and (f) PV (black contours; $\left.\mathrm{CI}=30 \times 10^{-12} \mathrm{~m}^{-1} \mathrm{~s}^{-1}\right)$ with $d S / d z\left(\mathrm{psu} / 100 \mathrm{~m}\right.$; colored shade) versus potential density $\left(\mathrm{kg} \mathrm{m}^{-3}\right)$.

IOSTMW (within 25.8-26.2 $\sigma_{\theta}$ ), another mode water (within 26.4-26.7 $\sigma_{\theta}$ ) which we call here "the second subtropical mode water", and SAMW (within 26.6-26.9 $\sigma_{\theta}$ ).

It is worth mentioning the similarities and differences of the $d T / d z$, PV and the vertical salinity gradient $(d T / d z)$ distributions along the $35.5^{\circ} \mathrm{S}$ line (Fig. $2 \mathrm{~b}-\mathrm{f}$ ). First, as a broad picture, the distribution of low $d S / d z$ (less than $0.1 \mathrm{psu} / 100 \mathrm{~m}$ ) corresponded to the distribution of low $d T / d z$ (less than $0.8^{\circ} \mathrm{C} / 100 \mathrm{~m}$ east of $50^{\circ} \mathrm{E}$, less than $1.0^{\circ} \mathrm{C} / 100 \mathrm{~m}$ in $40-50^{\circ} \mathrm{E}$ and less than $1.4^{\circ} \mathrm{C} / 100 \mathrm{~m}$ in $25-40^{\circ} \mathrm{E}$ ). This agreement was better than the low PV distribution, since higher $d S / d z$ (higher than $0.1 \mathrm{psu} / 100 \mathrm{~m}$ ) sometimes appeared in the lower PV region (less than $60 \times 10^{-12} \mathrm{~m}^{-1} \mathrm{~s}^{-1}$ in $55-80^{\circ} \mathrm{E}$ ). Second, there were three noticeable differences between the longitudinal $d T / d z$ structure and PV structure probably due to the salinity stratification. While the $d T / d z$ minimum appeared on $25.9-26.1 \sigma_{\theta}$ in $30-45^{\circ} \mathrm{E}$, the PV minimum did not appear in these density and longitudinal ranges. This difference may come from the salinity stratification (greater than $0.1 \mathrm{psu} / 100 \mathrm{~m}$ ) on $26.1-26.4 \sigma_{\theta}$ in 30 $40^{\circ} \mathrm{E}$ and $26.3-26.4 \sigma_{\theta}$ in $40-50^{\circ} \mathrm{E}$. In these areas, temperature and salinity compensate each other and they may form relatively homogeneous density stratification below the $d T / d z$ minimum. PV below the $d T / d z$ minimum could become as low as PV in the middle of $d T / d z$ minimum. In this case, a PV minimum did not appear on $25.9-26.1 \sigma_{\theta}$ in $30-45^{\circ} \mathrm{E}$. Next, while the $d T / d z$ minimum appeared on $26.4-26.8 \sigma_{\theta}$ in $25-40^{\circ} \mathrm{E}$, the PV minimum did not appear on $26.4-26.8 \sigma_{\theta}$ in $25-40^{\circ} \mathrm{E}$. This difference may also come from the salinity stratification (greater than $0.1 \mathrm{psu} / 100 \mathrm{~m}$ ) on $26.4-26.8 \sigma_{\theta}$ in $25-40^{\circ}$ E. Finally, while a $d T / d z$ minimum appeared on 26.4-26.6 $\sigma_{\theta}$ in $50-70^{\circ} \mathrm{E}$, a PV minimum appeared on 26.5$26.7 \sigma_{\theta}$ in $50-70^{\circ} \mathrm{E}$. Again, this difference may come from salinity stratification (greater than $0.1 \mathrm{psu} / 100 \mathrm{~m}$ ) denser than $26.6 \sigma_{\theta}$ in $50-70^{\circ} \mathrm{E}$. This salinity stratification may form a $\mathrm{PV}$ minimum on a denser isopycnal than the $d T / d z$ minimum by around $0.1 \sigma_{\theta}$. These facts suggest that focusing on $d T / d z$ structure is better than focusing on PV structure in order to find the remnant winter mixed layer in the Indian Ocean subtropical gyre especially within the IOSTMW density range $\left(25.8-26.2 \sigma_{\theta}\right)$. However, focusing on PV minimum is a good way to trace the advected water into the interior ocean under the assumption of PV conservation. 

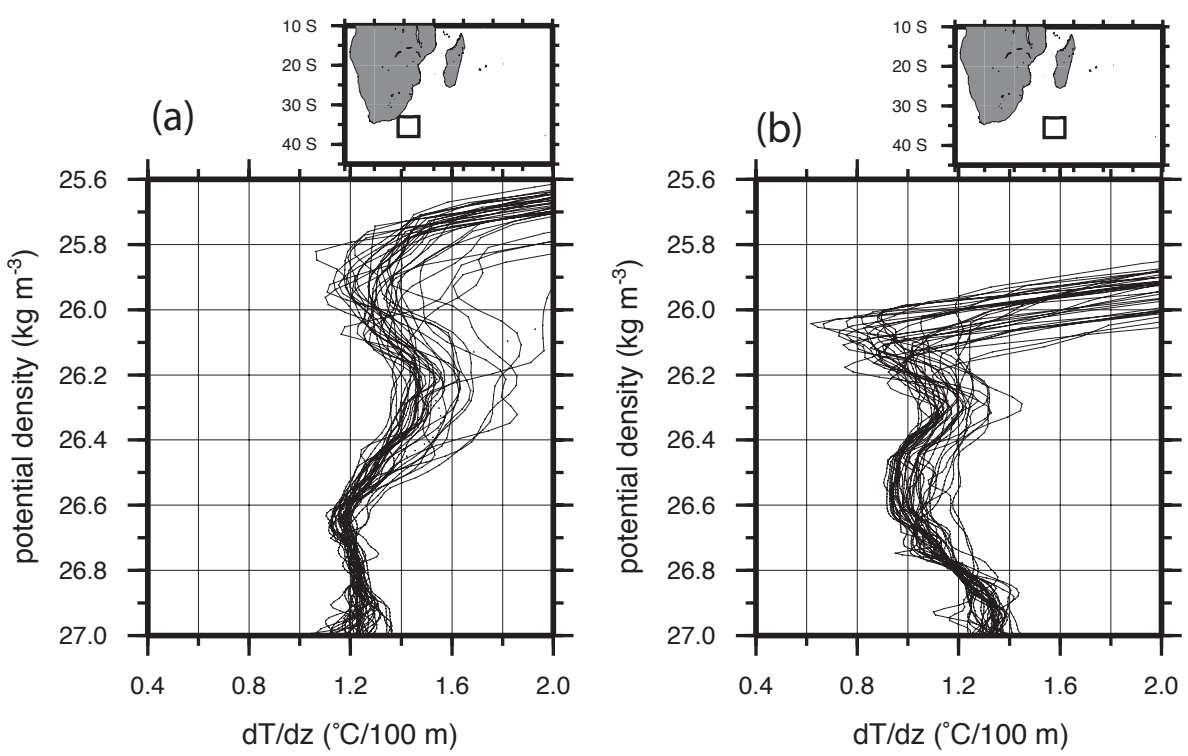

Fig. 3. Relationship between the $d T / d z\left({ }^{\circ} \mathrm{C} / 100 \mathrm{~m}\right)$ and potential density $\left(\mathrm{kg} \mathrm{m}^{-3}\right)$ in two selected sub-regions. The map shows the locations of Region A (33-38 $\mathrm{S}$ and $\left.28-35^{\circ} \mathrm{E}\right)$ and Region B (33-38 $\mathrm{S}$ and $\left.40-47^{\circ} \mathrm{E}\right)$.

\section{Water characteristics of the LMVTG}

We selected two sub-regions of the western part of the Indian Ocean subtropical gyre to characterise the $d T / d z$ structure (Fig. 3): Region A (33-38 $\mathrm{S}$ and $\left.28-35^{\circ} \mathrm{E}\right)$ and Region $\mathrm{B}\left(33-38^{\circ} \mathrm{S}\right.$ and $\left.40-47^{\circ} \mathrm{E}\right)$. In both sub-regions, each profile contained two LMVTG types: one denser and the other lighter than $26.3 \sigma_{\theta}$. The density range of each type was different in the two sub-regions. In Region $\mathrm{A}$, the denser LMVTG appeared around 26.6-26.7 $\sigma_{\theta}$ with a $d T / d z$ as low as $1.1^{\circ} \mathrm{C} / 100 \mathrm{~m}$, and the lighter LMVTG around $25.7-26.2 \sigma_{\theta}$ had a $d T / d z$ lower than $1.4{ }^{\circ} \mathrm{C} / 100 \mathrm{~m}$. In Region B, the denser LMVTG was around 26.4-26.7 $\sigma_{\theta}$ and the lighter LMVTG around 26.0-26.2 $\sigma_{\theta}$, both with a $d T / d z$ lower than $1.0^{\circ} \mathrm{C} / 100 \mathrm{~m}$. Since the lighter LMVTG appears as LMVTG A in the $35.5^{\circ} \mathrm{S}$ longitudinal $d T / d z$ section (Fig. 2b), the lighter LMVTG likely corresponds to the IOSTMW.

Although the lighter LMVTG existed in these sub-regions, we could not extract it objectively by applying any single threshold of $d T / d z$. As shown in Fig. 3, we could not detect the lighter LMVTG in Region A by applying a threshold of $1.0^{\circ} \mathrm{C} / 100 \mathrm{~m}$, which was an appropriate threshold for detecting the lighter LMVTG in Region B. The $d T / d z$ of the lighter LMVTG in Region A was higher than $1.0^{\circ} \mathrm{C} / 100 \mathrm{~m}$. Conversely, we could not detect the lighter LMVTG in Region B by applying a threshold of $1.4^{\circ} \mathrm{C} / 100 \mathrm{~m}$, which was an appropriate threshold for detecting the lighter LMVTG in Region A. The maximum $d T / d z$ below the lighter LMVTG in Region B was lower than $1.4{ }^{\circ} \mathrm{C} / 100 \mathrm{~m}$. This situation is different from that of other subtropical gyres. For example, we can detect the LMVTG corresponding to North Pacific STMW (Masuzawa, 1969; Suga and Hanawa, 1995) in the western part of the North Pacific subtropical gyre reasonably well by applying any single threshold of $d T / d z$ from 1.0 to $1.8^{\circ} \mathrm{C} / 100 \mathrm{~m}$. It is important to note that this does not signify the vulnerability of the LMVTG; rather, the weak temperature stratification below the LMVTG causes difficulty in detecting the LMVTG. If sufficient temperature stratification (greater than $2.0^{\circ} \mathrm{C} / 100 \mathrm{~m}$ ) had existed below the lighter LMVTG, we could have detected the lighter LMVTG in both sub-regions A and B reasonably by applying any single threshold of $d T / d z$ from 1.4 to $2.0^{\circ} \mathrm{C} / 100 \mathrm{~m}$.

We adapted a new method to extract multiple LMVTGs objectively from a single $d T / d z$ profile with weak temperature stratification. We changed the threshold of $d T / d z$ continuously from 2.0 to $0.0^{\circ} \mathrm{C} / 100 \mathrm{~m}$, at intervals of $0.02{ }^{\circ} \mathrm{C} / 100 \mathrm{~m}$. Because we also needed to take into account the denser LMVTG, multiple LMVTGs were extracted objectively. Figure 4 shows a schematic of this method with two typical vertical temperature structures. They were obtained at (a) $35.5^{\circ} \mathrm{S}, 32.5^{\circ} \mathrm{E}$ and (b) $35.5^{\circ} \mathrm{S}, 41.5^{\circ} \mathrm{E}$. In (a), the lighter LMVTG had a higher $d T / d z$ than the denser LMVTG, and in (b), the opposite was the case. In (a), the lighter LMVTG was detected with a $d T / d z$ threshold from 1.56 to $1.32{ }^{\circ} \mathrm{C} / 100 \mathrm{~m}$, while the denser LMVTG occurred from 1.22 to $1.18^{\circ} \mathrm{C} / 100 \mathrm{~m}$. In (b), the lighter LMVTG was detected from 1.20 to $0.86^{\circ} \mathrm{C} / 100 \mathrm{~m}$, while the denser LMVTG from 1.20 to $1.04^{\circ} \mathrm{C} / 100 \mathrm{~m}$. Therefore, we could detect multiple LMVTGs objectively from a single profile with weak temperature stratification using this method. As a trade-off, we could not examine the thickness of the LMVTG, which depends on the $d T / d z$ threshold. Therefore, we focused on the water characteristics of the LMVTG core, which do not depend on thickness. 

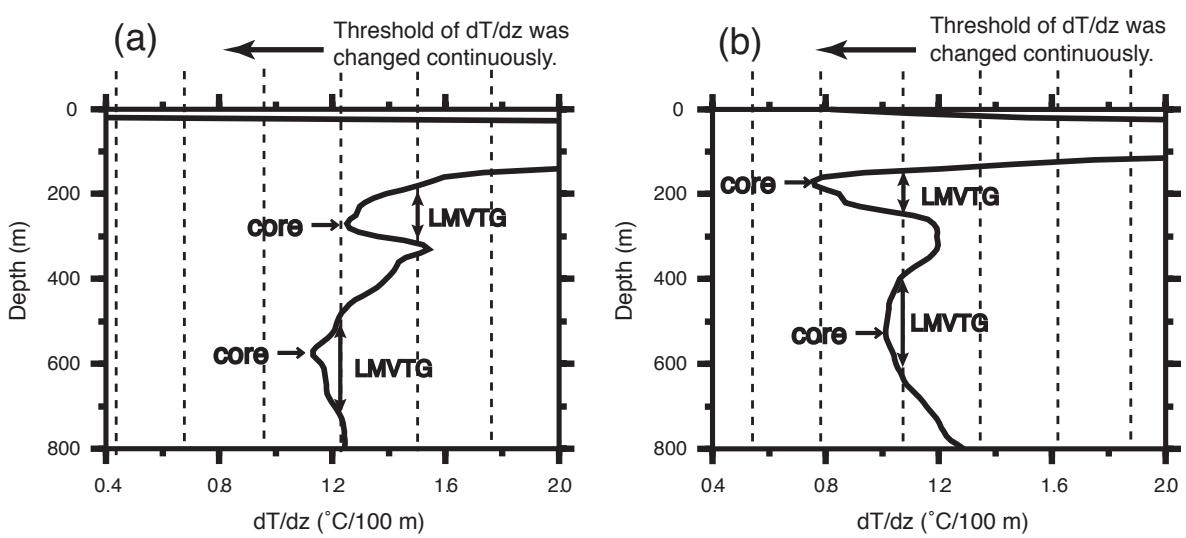

Fig. 4. A schematic of the method for detecting multiple LMVTGs from a single profile. Two typical $d T / d z$ profiles $\left({ }^{\circ} \mathrm{C} / 100 \mathrm{~m}\right)$ are shown: (a) $35.5^{\circ} \mathrm{S}, 32.5^{\circ} \mathrm{E}$ and (b) $35.5^{\circ} \mathrm{S}, 41.5^{\circ} \mathrm{E}$. The dotted line shows the threshold of $d T / d z$ which was varied continuously from 2.0 to $0.0^{\circ} \mathrm{C} / 100 \mathrm{~m}$ in $0.02{ }^{\circ} \mathrm{C} / 100 \mathrm{~m}$ intervals. Black arrows show the LMVTG detected with a certain $d T / d z$ threshold. Positions of LMVTG core are also shown.
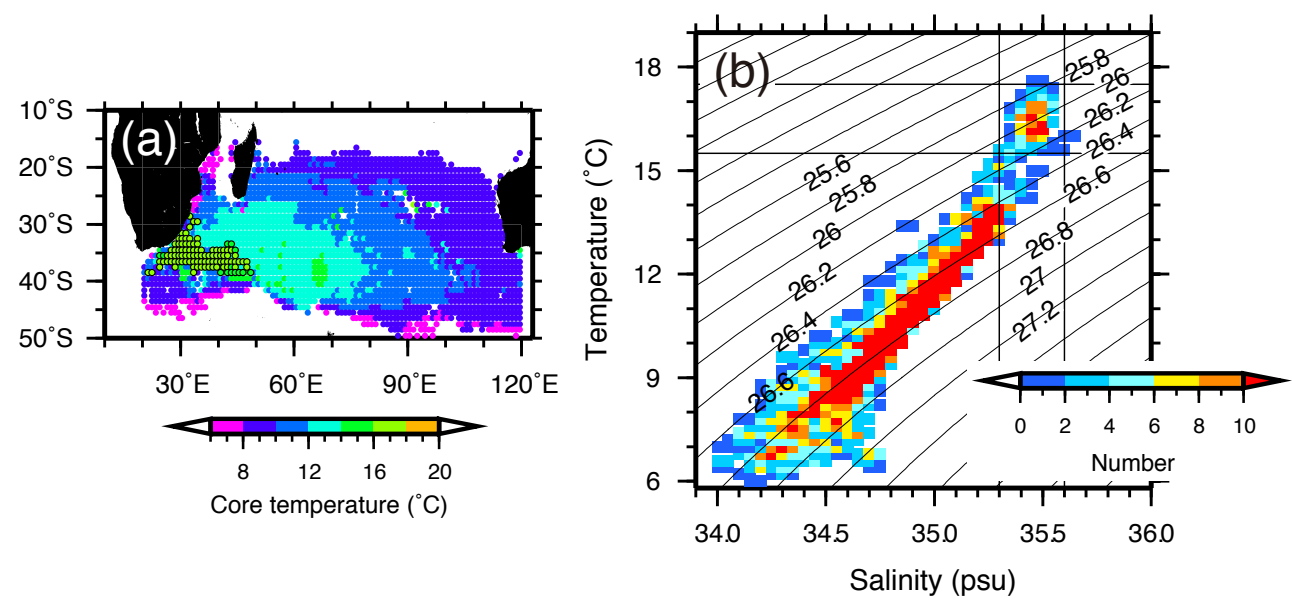

Fig. 5. (a) Spatial distribution of core temperature of LMVTG and (b) occurrence frequency of core water characteristics on the bivariate classes of temperature and salinity in the $10-50^{\circ} \mathrm{S}, 20-120^{\circ} \mathrm{E}$ region. When two cores are detected from a single $d T / d z$, profile, the higher core temperature is plotted on the spatial distribution of core temperature, and both core water characteristics are counted to calculate the occurrence frequency. In (a), core temperatures higher than $15.5^{\circ} \mathrm{C}$ are circled by a solid line.

We extracted water characteristics of the LMVTG core from a wide area $\left(10-50^{\circ} \mathrm{S}, 20-120^{\circ} \mathrm{E}\right)$ of the South Indian Ocean using this method. Generally, one core was extracted from a single $d T / d z$ profile north of $30^{\circ} \mathrm{S}$, while two cores were extracted on the north side of the STF and west of $70^{\circ} \mathrm{E}$, and on the north side of the SAF and east of $70^{\circ} \mathrm{E}$. Most of the second cores were detected in the density range denser than $26.5 \sigma_{\theta}$. Figure 5a shows that cores colder than $10^{\circ} \mathrm{C}$ corresponding to denser SAMW were distributed anticlockwise around the outer northeastern rim of the subtropical gyre. This characteristic agreed with previous studies (McCarthy and Talley, 1999; Wong, 2005). The core temperature was higher than $15.5^{\circ} \mathrm{C}$ between $33-38^{\circ} \mathrm{S}$ and $25-$ $50^{\circ} \mathrm{E}$. Figure $5 \mathrm{~b}$ shows that an area census of the core temperature and salinity reveals two bivariate modes around 8.0$14.0^{\circ} \mathrm{C}, 34.3-35.3 \mathrm{psu}$ and denser than $26.3 \sigma_{\theta}$, and around $15.5-17.5^{\circ} \mathrm{C}, 35.3-35.6 \mathrm{psu}$ and lighter than $26.3 \sigma_{\theta}$. The density and temperature ranges of the denser mode corresponded to that of SAMW and MLD C. The density and temperature ranges of the lighter mode corresponded to that of MLD A. Fewer LMVTG cores appeared on the density range of MLD B. It seems that water mass corresponding to MLD B does not subduct into the interior South Indian Ocean for some unknown reasons.

The core temperatures higher than $15.5^{\circ} \mathrm{C}$ were located in the western part of the Indian Ocean subtropical gyre, and the core water characteristics around $16.5^{\circ} \mathrm{C}$ and $35.5 \mathrm{psu}$ formed a maximum in occurrence frequency on the bivariate classes of temperature and salinity. MLD distribution (Fig. 1) and the distribution of $d T / d z$ along $35.5^{\circ} \mathrm{S}$ line (Fig. 2b) supported that this occurrence frequency maximum corresponded to one mode water. Therefore, we concluded that this mode water corresponds to IOSTMW. 
According to previous studies, it is reasonable to assume that the other much broader occurrence frequency maximum of core water characteristics around $8.0-14.0^{\circ} \mathrm{C}$ and $34.3-$ $35.3 \mathrm{psu}$ is due to two mode waters: the second subtropical mode water centered around $12.0-14.0^{\circ} \mathrm{C}$ and $35.0-35.4 \mathrm{psu}$ formed north of the STF, and SAMW around $8.0-10.0^{\circ} \mathrm{C}$ and 34.2-34.6 psu formed south of the STF. This interpretation is reasonable because the definition of the STF (10.0$12.0^{\circ} \mathrm{C}$ and $34.6-35.0 \mathrm{psu}$ at $100 \mathrm{dbar}$; Orsi et al., 1995) divides this broad maximum into two parts through the middle. Although these two mode waters did not appear as two occurrence frequency maxima, the MLD maxima distribution (Fig. 1) and the distribution of $d T / d z$ along $35.5^{\circ} \mathrm{S}$ line (Fig. 2a, b) suggested that they are independent mode waters. Therefore, water characteristics of the second subtropical mode water were estimated based on winter mixed layer water characteristics in September (Fig. 1). Sea-surface water characteristics with MLD greater than $200 \mathrm{~m}$, in the $57-75^{\circ} \mathrm{E}$ longitudinal band and north of STF were averaged. The averaged water characteristics and the standard deviations were $12.84 \pm 0.57^{\circ} \mathrm{C}, 35.17 \pm 0.11 \mathrm{psu}$ and $26.57 \pm 0.04 \sigma_{\theta}$. These averaged water characteristics agreed with McDonagh et al. (2005) and this density range agreed with that of LMVTG B (Fig. 2b).

We calculated the averaged IOSTMW water characteristics. All core temperatures higher than $15.5^{\circ} \mathrm{C}$ were counted. The averaged IOSTMW water characteristics and standard deviations were $16.54 \pm 0.49^{\circ} \mathrm{C}, 35.51 \pm 0.04 \mathrm{psu}$, and $26.0 \pm 0.1 \sigma_{\theta}$. According to Bryden et al. (2003), upper thermocline waters $\left(10.0-17.0^{\circ} \mathrm{C}\right)$ along the $32^{\circ} \mathrm{S}$ hydrographic line showed substantial oscillations during 19362002. To examine the time period that this averaged IOSTMW water property represented, we investigated the source data used to construct the IOHB. The source data obtained in the region $30-40^{\circ} \mathrm{S}$ and $20-50^{\circ} \mathrm{E}$ during JanuaryMarch were mainly from the period of 1960-2004, with peaks in the 1970s and 1990s. Therefore, we concluded that this averaged water property represented approximately the time period from 1960 to 2004 .

The water characteristics of the IOSTMW specified above were compared with those described in previous studies. The temperature specified in the present study was about $1{ }^{\circ} \mathrm{C}$ lower than that reported by Olson et al. (1992). The temperature difference between our results and theirs was presumably due to the difference in the analysed area. The IOSTMW core temperature varies spatially, as indicated in Fig. 3, with lighter density (higher temp.) values in the west. While the IOSTMW in Region A had a core density of approximately $25.9 \pm 0.2 \sigma_{\theta}$ and a core temperature of approximately $17.0 \pm 1.0^{\circ} \mathrm{C}$, the IOSTMW in Region B had a core density of approximately $26.1 \pm 0.1 \sigma_{\theta}$ and a core temperature of approximately $16.5 \pm 0.5^{\circ} \mathrm{C}$. We expect our results to represent the IOSTMW water characteristics more accurately because we treated the core temperature more carefully over a wider region of the Indian Ocean subtropical gyre.

\section{Spatial distribution of IOSTMW}

In this section, we show the limitations of the LMVTG as a tool for describing the spatial extent of IOSTMW and examine the spatial distribution of IOSTMW from a different viewpoint. While the North Pacific Central Mode Water (Nakamura, 1996; Suga et al., 1997) forms LMVTG only in the $35-40^{\circ} \mathrm{N}, 160^{\circ} \mathrm{E}-160^{\circ} \mathrm{W}$ region, its signature as a lateral minimum of low PV on the $26.4 \sigma_{\theta}$ isopycnal surface spreads widely southward down to $20^{\circ} \mathrm{N}$ from the formation area along the gyre flow path (Suga et al., 2004). In an area of weakly stratified temperature structure below the mode water, the distribution of the lateral minimum of low PV does not always correspond to the distribution area of the LMVTG.

Figure 6a shows the distribution of PV on the $26.1 \sigma_{\theta}$ isopycnal surface, where the IOSTMW water characteristics formed a modal class of temperature and salinity for the area census (Fig. 5b). The lateral minimum of low PV (less than $300 \times 10^{-12} \mathrm{~m}^{-1} \mathrm{~s}^{-1}$ ) on the $26.1 \sigma_{\theta}$ isopycnal surface was distributed over the $27-38^{\circ} \mathrm{S}, 25-50^{\circ} \mathrm{E}$ region. While the southern part of this low PV corresponded quite well to the distribution area of the LMVTG, the northern part did not. Through careful examination of the northern part, we confirmed that the $15.5-17.5^{\circ} \mathrm{C}$ layer contained $d T / d z$ as low as $1.3^{\circ} \mathrm{C} / 100 \mathrm{~m}$. This layer did not form the LMVTG because no stronger temperature stratification existed below the 15.5$17.5^{\circ} \mathrm{C}$ layer. Since the water mass is generally advected on the isopycnal surface, it is reasonable to consider that the whole region of the lateral minimum of PV is a remnant of the winter mixed layer. Therefore, we concluded that a PV of less than $300 \times 10^{-12} \mathrm{~m}^{-1} \mathrm{~s}^{-1}$ on the $26.1 \sigma_{\theta}$ isopycnal surface represented the IOSTMW region more accurately.

We calculated the thickness of the $15.5-17.5^{\circ} \mathrm{C}$ layer which is equivalent to a low PV value of $300 \times 10^{-12} \mathrm{~m}^{-1} \mathrm{~s}^{-1}$ under some assumptions. The temperature range of $15.5-$ $17.5^{\circ} \mathrm{C}$ corresponded to the IOSTMW core temperature range (Fig. 4b). Assuming that the relative vorticity is negligible and the vertical salinity stratification is fixed, the thickness of the $15.5-17.5^{\circ} \mathrm{C}$ layer can be calculated based on Eq. (1)

$P V \approx-\frac{f}{\rho} \frac{\partial \rho}{\partial z}=f\left(\alpha \frac{\partial T}{\partial z}-\beta \frac{\partial S}{\partial z}\right)$

$\rho$ is the averaged IOSTMW potential density, $\alpha$ is a thermal expansion coefficient, $\beta$ is a saline contraction coefficient and $f$ is the coriolis parameter. The $\alpha$ and $\beta$ were calculated using the averaged IOSTMW water characteristics, and the $f$ was varied for $27-38^{\circ} \mathrm{S}$. Representative $d S / d z$ was taken as $0.07 \pm 0.03 \mathrm{psu} / 100 \mathrm{~m}$ considering the horizontal and vertical variation of $d S / d z$ within the IOSTMW. The mean and standard deviation of $d S / d z$ calculated from the LMVTG core higher than $15.5^{\circ} \mathrm{C}$ were $0.066 \pm 0.031 \mathrm{psu} / 100 \mathrm{~m}$. The $d S / d z$ within the IOSTMW (LMVTG A) along the $35.5^{\circ} \mathrm{S}$ zonal section were less than $0.1 \mathrm{psu} / 100 \mathrm{~m}$ (Fig. 2). Under 

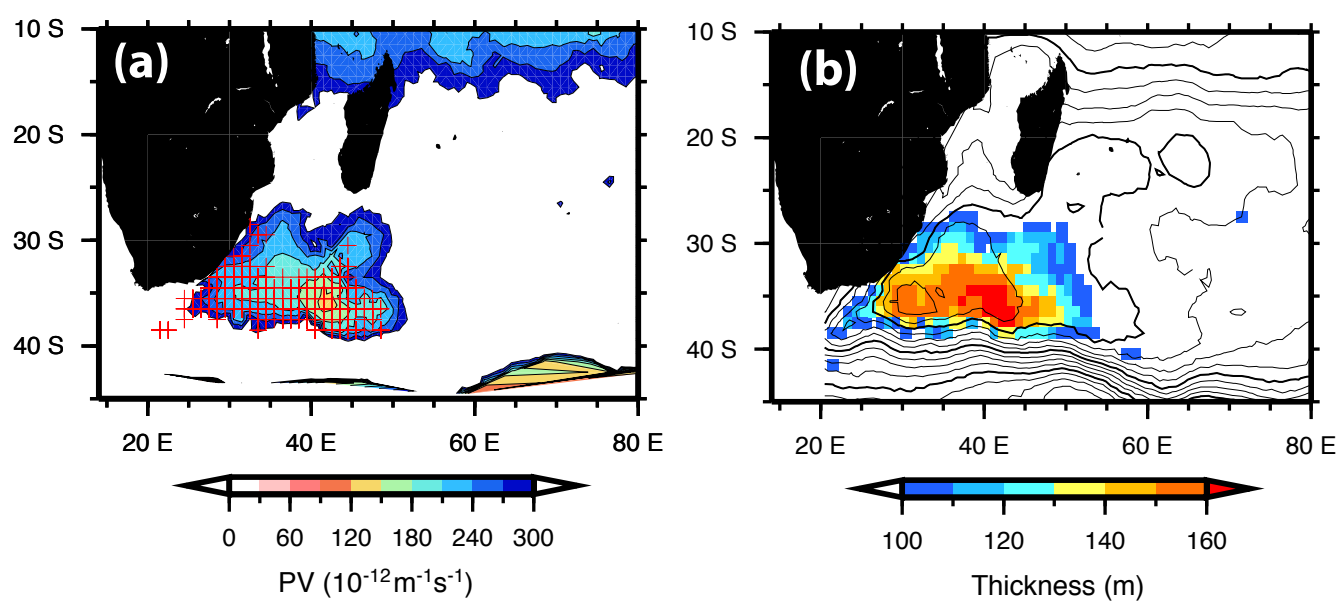

Fig. 6. (a) Distribution of PV $\left(10^{-12} \mathrm{~m}^{-1} \mathrm{~s}^{-1}\right)$ on the $26.1 \sigma_{\theta}$ isopycnal surface. The crosses represent all LMVTG positions with a core temperature higher than $15.5^{\circ} \mathrm{C}$, which are detected by changing the threshold of vertical temperature gradient continuously from $2.0{ }^{\circ} \mathrm{C} / 100 \mathrm{~m}$ to $0.0{ }^{\circ} \mathrm{C} / 100 \mathrm{~m}$ at $0.02{ }^{\circ} \mathrm{C} / 100 \mathrm{~m}$ intervals. (b) The spatial distribution of the thickness of the $15.5-17.5^{\circ} \mathrm{C}$ layer greater than $100 \mathrm{~m}$ is superimposed on the dynamic height $\left(\mathrm{m}^{2} \mathrm{~s}^{-2}\right)$ at $200 \mathrm{~m}$ relative to $1000 \mathrm{~m}$.

(a) $26.5 \sigma_{\theta}$

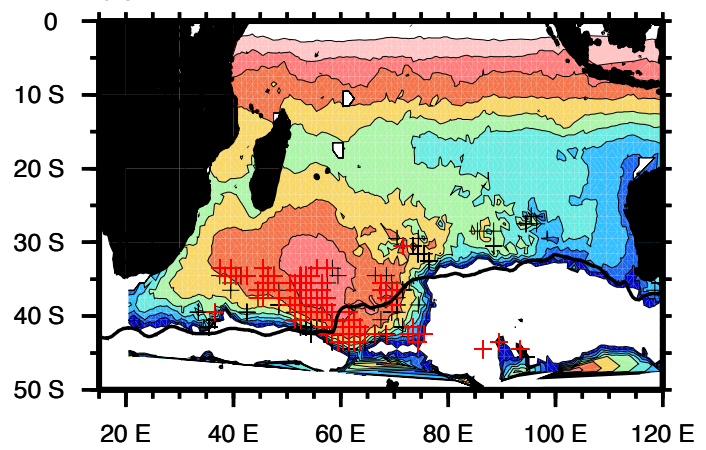

(c) $26.7 \sigma_{\theta}$

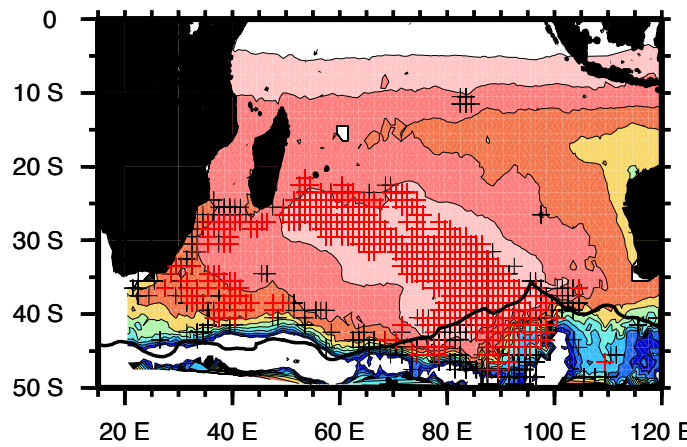

(b) $26.6 \sigma_{\text {o }}$

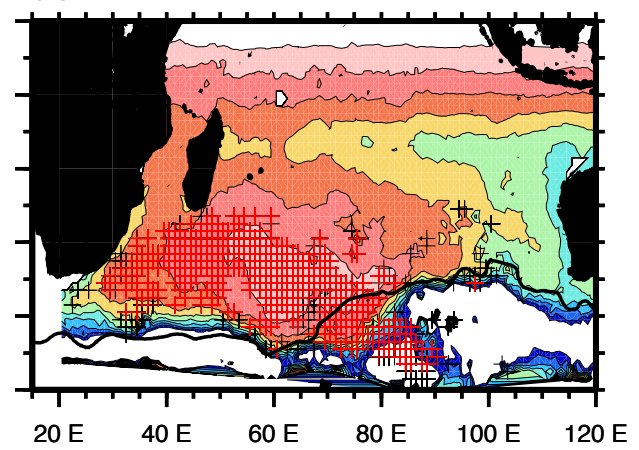

(d) $26.8 \sigma_{\theta}$

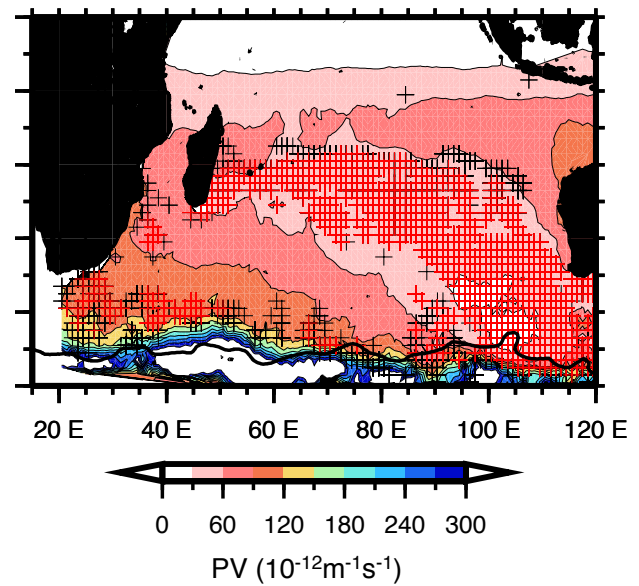

Fig. 7. (a) Distribution of PV $\left(10^{-12} \mathrm{~m}^{-1} \mathrm{~s}^{-1}\right)$ on the $26.5 \sigma_{\theta}$ isopycnal surfaces. The black crosses represent all LMVTG positions and red crosses represent LMVTG positions greater than $200 \mathrm{~m}$ within $26.45-26.55 \sigma_{\theta}$. Mixed layer density of $26.5 \sigma_{\theta}$ in September is also shown in a bold black contour. (b) same as (a), but for PV on 26.6 $\sigma_{\theta}$ and LMVTG within 26.55-26.65 $\sigma_{\theta}$, (c) same as (a), but for PV on $26.7 \sigma_{\theta}$ and LMVTG within 26.65-26.75 $\sigma_{\theta}$ and (d) same as (a), but for PV on 26.8 $\sigma_{\theta}$ and LMVTG within 26.75-26.85 $\sigma_{\theta}$. 
this assumption, the calculated thickness was $97 \pm 18 \mathrm{~m}$. The uncertainty came mainly from the variation of the coriolis parameter. The area where the $15.5-17.5^{\circ} \mathrm{C}$ layer was greater than $100 \mathrm{~m}$ corresponded fairly well to the distribution area of low PV less than $300 \times 10^{-12} \mathrm{~m}^{-1} \mathrm{~s}^{-1}$ on the $26.1 \sigma_{\theta}$ isopycnal surface (Fig. 6b). Thus, we suggest that the area of the $15.5-17.5^{\circ} \mathrm{C}$ layer greater than $100 \mathrm{~m}$ roughly represents the IOSTMW distribution area.

\section{Conclusions}

We have improved the basic description (water characteristics and spatial distribution) of the IOSTMW using an isopycnally averaged three-dimensional hydrographic dataset. Following the STMW definition of Hanawa and Talley (2001), we defined the IOSTMW as the mode water adjacent to the Agulhas currents with single mode of water characteristics. From this point-of-view, we clarified the relationships between several mode waters in the Indian Ocean subtropical gyre (north of STF). As reported by previous studies, two mode waters and their corresponding MLD maxima were observed north of the STF: IOSTWM (within $25.8-26.2 \sigma_{\theta}$ ) in $28-45^{\circ} \mathrm{E}$ and a second subtropical mode water in the subtropical gyre (within 26.4-26.7 $\sigma_{\theta}$ ) in the $60-80^{\circ} \mathrm{E}$ longitudinal band. We found that we could not detect the whole IOSTMW as an LMVTG using any single $d T / d z$ threshold because temperature stratification below the IOSTMW was weak. By changing the threshold of $d T / d z$ continuously, we confirmed that a substantial mass of LMVTG was located in the western part of the Indian Ocean subtropical gyre and that its core water characteristics formed a mode on the bivariate classes of temperature and salinity for the area census. Thus, we concluded that this mass of LMVTG corresponds to IOSTMW. The averaged water characteristics of the IOSTMW approximately during 1960-2004 were $16.54 \pm 0.49^{\circ} \mathrm{C}, 35.51 \pm 0.04 \mathrm{psu}$ and $26.0 \pm 0.1 \sigma_{\theta}$. The temperature of the IOSTMW was about $1{ }^{\circ} \mathrm{C}$ lower than that reported in previous studies. The IOSTMW was distributed in $25-50^{\circ} \mathrm{E}, 27-38^{\circ} \mathrm{S}$. This area had a lateral minimum of low PV (less than $300 \times 10^{-12} \mathrm{~m}^{-1} \mathrm{~s}^{-1}$ ) on the $26.1 \sigma_{\theta}$ isopycnal surface where the IOSTMW water characteristics formed a mode on the bivariate classes of temperature and salinity. The IOSTMW distribution area was also approximated as the area where the thickness of the 15.5$17.5^{\circ} \mathrm{C}$ layer was greater than $100 \mathrm{~m}$. The formation region and approximate water characteristics of the second subtropical mode water in the subtropical gyre were also presented. Its probable formation region was $37-42^{\circ} \mathrm{S}$ and $60-80^{\circ} \mathrm{E}$ in longitudinal band and north of the STF. Its approximate water characteristics were $12.84 \pm 0.57^{\circ} \mathrm{C}, 35.17 \pm 0.11 \mathrm{psu}$ and $26.57 \pm 0.04 \sigma_{\theta}$.

Figure 7 shows the distribution of PV on $26.5-26.8 \sigma_{\theta}$ isopycnal surfaces based on the summer averaged IOHB dataset in order to illustrate how these different layers may be ventilated in the South Indian Ocean subtropical gyre for future studies. The positions of LMVTG thicker than $200 \mathrm{~m}$ within $26.45-26.55 \sigma_{\theta}$ are also plotted on $26.5 \sigma_{\theta}$ isopycnal surfaces. A thicker thickness criterion was applied because typical vertical scales of the thermostat in this density range (denser than $26.4 \sigma_{\theta}$ ) are larger than that of the IOSTMW density range (Fig. 2a). Low PV (less than $120 \times 10^{-12} \mathrm{~m}^{-1} \mathrm{~s}^{-1}$ ) on the $26.5 \sigma_{\theta}$ isopycnal surfaces spreads anticlockwise in the southwestern part of the Indian Ocean subtropical gyre from its winter outcrop area, while low PV (less than $60 \times 10^{-12} \mathrm{~m}^{-1} \mathrm{~s}^{-1}$ ) on the $26.8 \sigma_{\theta}$ surface (denser SAMW) spreads anticlockwise along the northeastern rim of Indian Ocean subtropical gyre from their formation region. The correspondence between the positions of LMVTG and low PV distribution on each isopycnal layer suggests that these low PV distributions represent the flow path of the remnant winter deep mixed layer. Therefore, we suggest that the second subtropical mode water may ventilate in the southwestern part of the Indian Ocean subtropical gyre. However, the relationship between the positions of LMVTG and low PV distribution and the relationship to the flow field should be examined carefully. As shown in Fig. $2 b$ and $2 c$, the PV minimum on $26.5-26.7 \sigma_{\theta}$ in 50 $70^{\circ} \mathrm{E}$ appeared deeper than the depth of the $d T / d z$ minimum by around $0.1 \sigma_{\theta}$. Using the Argo data, the SODB and an ocean general circulation model, new studies about South Indian Ocean ventilation are in progress (Sallee et al., 2009; Koch-Larrouy et al., 2009). Detailed examination and interpretation will be left for future studies.

Acknowledgements. Mixed layer data calculated from the Argo data and the SODB was provided by Jean-Baptiste Sallee. The comments from two anonymous referees have improved this paper. This study was performed as a part of the 21st Century Center-of-Excellence (COE) Program "Advanced Science and Technology Center for Dynamic Earth (E-ASTEC)" at Tohoku University.

Edited by: A. J. George Nurser

\section{References}

Akima, H.: A new method of interpolation and smooth curve fitting based on local procedures, J. Assoc. Comput. Math., 17, 589602, 1970.

Aoki, S., Hariyama, M., Mitsudera, H., Sasaki, H., and Sasai, Y.: Formation regions of Subantarctic Mode Water detected by OFES and Argo profiling floats, Geophys. Res. Lett., 34, L10606, doi:10.1029/2007GL029828, 2007.

Boyer, T. P., Stephens, C., Antonov, J. I., Conkright, M. E., Locarnini, R. A., O'Brien, T. D., and Garcia, H. E.: World Ocean Atlas 2001, Vol. 2, Salinity, NOAA Atlas NESDIS 50, CDROM., 2002.

Bryden, H. L., McDonagh, E. L., and King, B. A.: Changes in ocean water mass properties: Oscillations or trends?, Science, 300, 2086-2088, 2003. 
Fine, R. A.: Circulation of Antarctic Intermediate Water in the South Indian-Ocean, Deep-Sea Res., 40, 2021-2042, 1993.

Hanawa, K. and Sugimoto, S.: "Reemergence" areas of winter sea surface temperature anomalies in the world's oceans, Geophys. Res. Lett., 31, L10303, doi:10.1029/2004GL01904, 2004.

Hanawa, K. and Talley, L. D.: Mode Waters, Ocean Circulation and Climate, in: Observing and Modelling the Global Ocean, edited by: Siedler, G., Church, J., and Gould, J., Academic Press, London, 373-386, 2001.

Kobayashi, T. and Suga, T.: The Indian Ocean HydroBase: A high-quality climatological dataset for the Indian Ocean, Prog. Oceanogr., 68, 75-114, 2006.

Koch-Larrouy, A., Morrow, R., Penduff, T., and Juza, M.: Origin and mechanism of Sub Antarctic Mode Water formation and transformation in the Southern Indian Ocean, Ocean Dynamics, in revision, 2010.

Marshall, J. C., Nurser, A. J. G., and Williams, R. G.: Inferring the Subduction Rate and Period over the North-Atlantic, J. Phys. Oceanogr., 23, 1315-1329, 1993.

Masuzawa, J.: Subtropical mode water, Deep-Sea Res., 16, 453472, 1969

McCarthy, M. C. and Talley, L. D.: Three-dimensional isoneutral potential vorticity structure in the Indian Ocean, J. Geophys. Res., 104(C6), 13251-13267, 1999.

McCartney, M. S.: Subantarctic Mode Water, A Voyage of Discovery, in: George Deacon 70th Anniversary Volume, edited by: Angel, M., Pergamon Press, Oxford 103-199, 1977.

McCartney, M. S.: The subtropical recirculation of mode waters., J. Mar. Res., 40 (Suppl.), 427-464, 1982.

McDonagh, E. L., Bryden, H. L., King, B. A., Sanders, R. J., Cunningham, S. A., and Marsh, R.: Decadal changes in the south Indian Ocean thermocline, J. Climate, 18, 1575-1590, 2005.

Nakamura, H.: A pycnostad on the bottom of the ventilated portion in the central subtropical North Pacific: Its distribution and formation, J. Oceanogr., 52, 172-188, 1996.

Olson, D. B., Fine, R. A., and Gordon, A. L.: Convective modification of water masses in the Agulhas?, Deep-Sea Res., 39, S163-S181, 1992.
Orsi, A. H., Whitworth, T., and Nowlin, W. D.: On the Meridional Extent and Fronts of the Antarctic Circumpolar Current, DeepSea Res., 42, 641-673, 1995.

Ridgway, K. R., Dunn, J. R., and Wilkin, J. L.: Ocean interpolation by four-dimensional weighted least squares - application to the waters around Australasia, J. Atmos. Oceanic Technol., 19, 1357-1375, 2002.

Rintoul, S. R. and England, M. H.: Ekman transport dominates airsea fluxes in driving variability of Subantarctic Mode Water, J. Phys. Oceanogr., 32, 1308-1321, 2002.

Sallee, J. B., Speer, K., and Morrow, R.: Response of the Antarctic Circumpolar Current to atmospheric variability, J. Climate, 21, 3020-3039, 2008.

Sallee, J. B., Speer, K., Rintoul, S. R. and Wijffels, S.: Southern Ocean thermocline ventilation, J. Phys. Oceanogr., doi:10.1175/2009JPO4291.1, 2010.

Sallee, J. B., Wienders, N., Speer, K., and Morrow, R.: Formation of subantarctic mode water in the southeastern Indian Ocean, Ocean Dynamics, 56, 525-542, 2006.

Stephens, C., Antonov, J. I., Boyer, T. P., Conkright, M. E., Locarnini, R. A., O’Brien, T. D., and Garcia, H. E.: World Ocean Atlas 2001, Vol. 1, Temperature, NOAA Atlas NESDIS 49, CDROM., 2002.

Suga, T. and Hanawa K.: The Subtropical Mode Water Circulation in the North Pacific, J. Phys. Oceanogr., 25, 958-970, 1995.

Suga, T., Motoki, K., Aoki, Y., and Macdonald, A. M.: The North Pacific climatology of winter mixed layer and mode waters, J. Phys. Oceanogr., 34, 3-22, 2004.

Suga, T., Takei, Y., and Hanawa, K.: Thermostad Distribution in the North Pacific Subtropical Gyre: The Central Mode Waters and the Subtropical Mode Water, J. Phys. Oceanogr., 27, 140$152,1997$.

Toole, J. M. and Warren, B. A.: A hydrographic section across the south Indian-Ocean, Deep-Sea Res., 40, 1973-2019, 1993.

Wong, A. P. S.: Subantarctic Mode Water and Antarctic Intermediate Water in the South Indian Ocean based on profiling float data 2000-2004, J. Mar. Res., 63, 789-812, 2005. 